archives

of thermodynamics

Vol. 38(2017), No. 1, 75-90

DOI: $10.1515 /$ aoter-2017-0005

\title{
Improving flexibility characteristics of 200 MW unit
}

\author{
JAN TALER ${ }^{a *}$ \\ MARCIN TROJAN ${ }^{a}$ \\ DAWID TALER ${ }^{b}$ \\ PIOTR DZIERWA ${ }^{a}$ \\ KAROL KACZMARSKI ${ }^{a}$
}

a Institute of Thermal Power Engineering, Cracow University of Technology, Jana Pawła II 37, 31-864 Kraków, Poland

2 Institute of Thermal Engineering and Air Protection, Faculty of Environmental Engineering, Warszawska 24, 31-155 Kraków, Poland

\begin{abstract}
Calculations were performed of the thermal system of a power plant with installed water pressure tanks. The maximum rise in the block electric power resulting from the shut-off of low-pressure regenerative heaters is determined. At that time, the boiler is fed with hot water from water pressure tanks acting as heat accumulators. Accumulation of hot water in water tanks is also proposed in the periods of the power unit small load. In order to lower the plant electric power in the off-peak night hours, water heated in low-pressure regenerative heaters and feed water tank to the nominal temperature is directed to water pressure tanks. The water accumulated during the night is used to feed the boiler during the period of peak demand for electricity. Drops in the power block electric power were determined for different capacities of the tanks and periods when they are charged. A financial and economic profitability analysis (of costs and benefits) is made of the use of tanks for a $200 \mathrm{MW}$ power unit. Operating in the automatic system of frequency and power control, the tanks may also be used to ensure a sudden increase in the electric power of the unit. The results of the performed calculations and analyses indicate that installation of water pressure tanks is well justified. The investment is profitable. Water pressure tanks may not only be used to reduce the power unit power during
\end{abstract}

\footnotetext{
${ }^{*}$ Corresponding Author. E-mail: taler@mech.pk.edu.pl
} 
the off-peak night hours and raise it in the periods of peak demand, but also to increase the power capacity fast at any time. They may also be used to fill the boiler evaporator with hot water during the power unit start-up from the cold state.

Keywords: Thermal power unit; Flexibility increasing; Steam boiler; Rapid start-up

\section{Nomenclature}

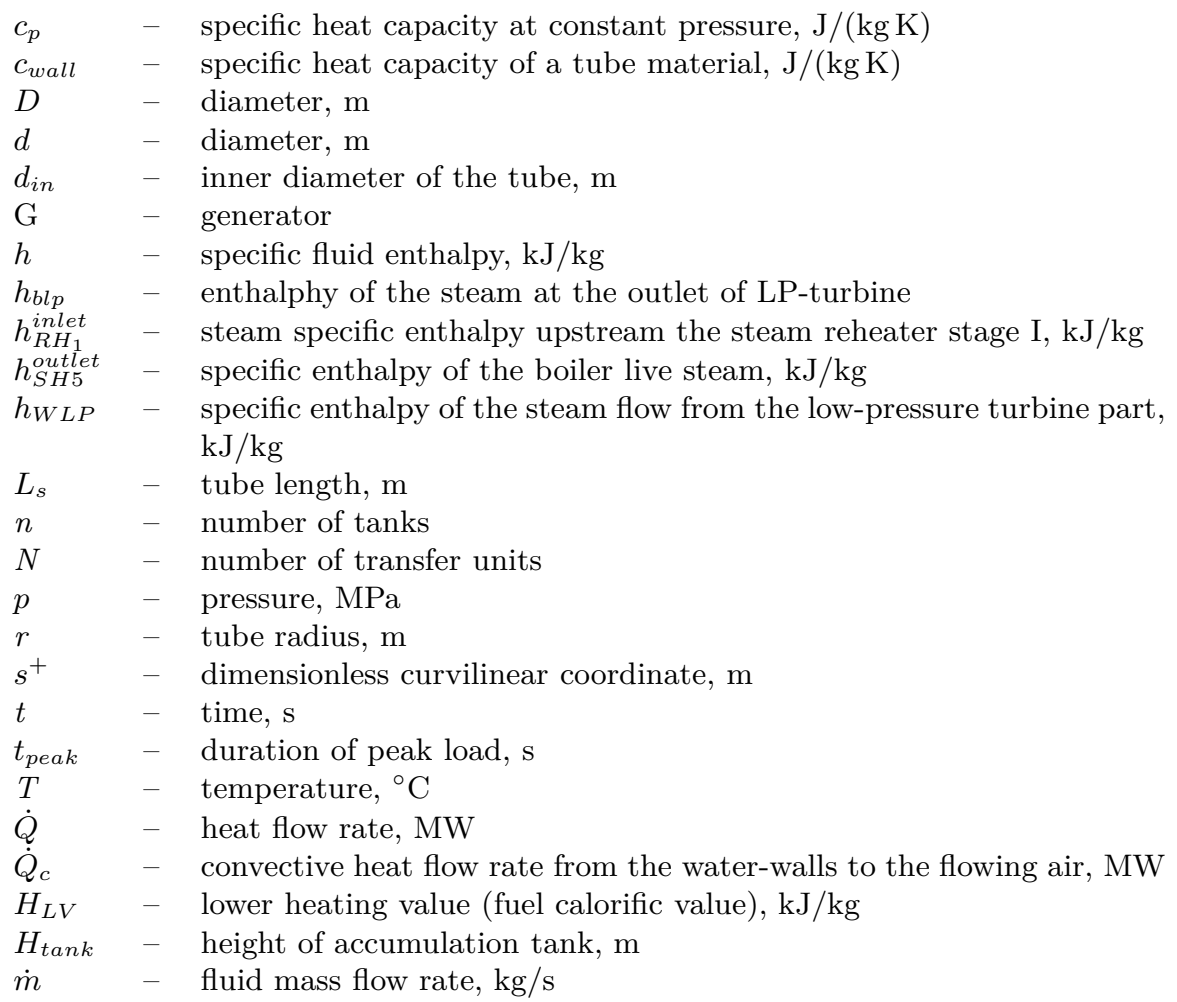

\section{Greek symbols}

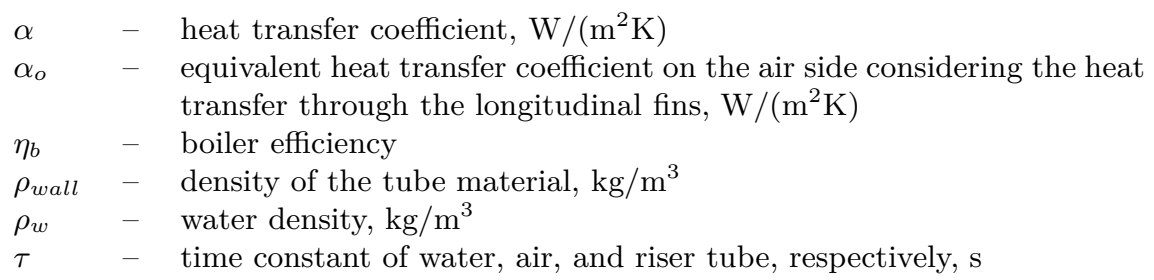




\section{Subscripts and superscripts}

$\begin{array}{lll}\infty & - & \text { ambient temperature } \\ I, \ldots, V I I & - & \text { bleed steam } \\ a & - & \text { air } \\ b & - & \text { boiler } \\ B R & - & \text { brine } \\ F W & - & \text { feed water } \\ i & - & \text { initial } \\ i n & - & \text { inner } \\ I P & - & \text { intermediate-pressure turbine } \\ h w & - & \text { hot water } \\ H P & - & \text { high-pressure turbine } \\ L P & - & \text { low-pressure turbine } \\ L S & - & \text { live steam } \\ n o m & - & \text { nominal (design) temperature } \\ \text { out } & - & \text { outer } \\ R H & - & \text { steam reheater } \\ S H & - & \text { live steam superheater stage } \\ w & - & \text { riser tube wall, water } \\ \text { wall } & - & \text { outer }\end{array}$

\section{Introduction}

Due to the rapid development of wind farms, photovoltaic cells, and other dispersed energy sources, considerable oscillations occur in electric power generation. If a power shortage is created in the electric power system, electricity needs to be supplied to the power grid quickly by thermal power plants. A requirement is also imposed on state-of-the-art power units to make it possible to raise or lower the power capacity at the rate of $2-8 \%$ of installed power per minute in the full range of control, i.e., from the minimum to the maximum load. The power unit start-up from different states should also proceed fast. The manufacturer of state-of-the-art power units is obliged to carry out the following tests:

- start-up from the cold state (after $8 \mathrm{~h}$ of unit standstill),

- start-up from the hot state (alter 8 to $50 \mathrm{~h}$ of unit standstill),

- start-up from the cold state (after more than 50 hours of unit standstill).

This paper presents an analysis of the possibility of using hot water pressure tanks to improve a $200 \mathrm{MW}$ power unit flexibility. The tanks may be used in the off-peak night hours to reduce the power unit power capacity due to 
low demand for electricity. In the period of low demand, the boiler may operate at the minimum permissible load (at the level of the boiler technical minimum), and steam is then used both to generate electrical energy and to heat up hot water accumulated in the tanks.

In the period of peak demand for electricity, which in Poland is between 4 p.m. and 10 p.m., the power unit capacity may be raised. Low-pressure regenerative bleeds are then shut off, which involves a rise in the electric power of the block due to a bigger mass flow of steam through the turbine. The boiler is fed with hot water accumulated in the tanks.

Hot water tanks may also be used to fill the boiler with hot water at the beginning of the boiler start-up. According to the boiler drum optimal heating method proposed in [1-3], the boiler evaporator together with the drum may be flooded with hot water with a temperature much higher than the initial one. The pressure tank hot water may be used to feed the bottom headers of the boiler furnace chamber walls, and the water displaced from the boiler evaporator may be directed to the bottom part of the pressure tank. Owing to such heat accumulators, the boiler start-up from the cold state becomes faster and safer.

Hot water pressure tanks may also be used in the automatic system of frequency and power control to ensure a sudden increase in the power unit electric power. Shutting off low-pressure regenerative bleeds and feeding the boiler with hot water from the tanks, it is possible to raise the power unit maximum power capacity by more than $7 \%$ in several hours.

In this paper, a mathematical model for an optimum heating the boiler evaporator with hot water is presented. Also, the power increase in the peak load using water pressure accumulators and power reduction during the night by closing turbine bleeds are calculated.

\section{Model of the evaporator tube heating}

To simulate heating boiler evaporator mathematical models of water walls and downcomers (Fig. 1) were developed. The cold air flows through the combustion chamber during evaporator heating. The outer surfaces of the downcomers are thermally insulated.

A differential form of the energy conservation equation for water flowing through the evaporator tubes and the energy conservation equation for the evaporator tube wall will be derived first. 


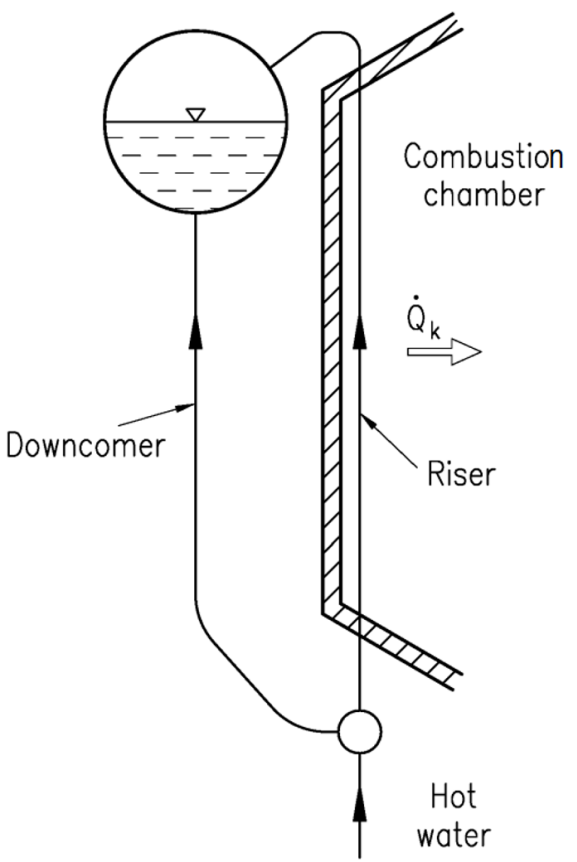

Figure 1: Diagram of water cooling and metal heating in the evaporator after it is suddenly filled with hot water.

\subsection{Energy balance equation for water flowing through the evaporator and the riser tubes}

Transforming the energy balance equation for a control volume with length $\Delta s \rightarrow 0$, the following is obtained

$$
\tau_{w} \frac{\partial T_{w}}{\partial t}+\frac{1}{N_{w}} \frac{\partial T_{w}}{\partial s^{+}}=-\left(T_{w}-T_{w a l l}\right),
$$

where

$$
N_{w}=\frac{\alpha_{w} \pi d_{i n} L_{s}}{\dot{m}_{w} c_{w}} \text { and } \tau_{w}=\frac{d_{i n}}{4 \alpha_{w}} \rho_{w} c_{w} .
$$

It is assumed that at the time $t=0$ the temperature of water in the evaporator tubes is constant and equal to ambient temperature $T_{\infty}$, i.e., the initial condition is expressed as

$$
\left.T_{w}\right|_{t=0}=T_{\infty} .
$$


Hot water with temperature $T_{h w}$ flows into the riser tubes through lower headers to the boiler waterwalls and the boundary condition is of the following form:

$$
\left.T_{w}\right|_{s^{+}=0}=T_{h w} .
$$

Equation (1) with conditions (3)-(4) have been solved using the finite difference method.

\subsection{Energy balance equation for the waterwall tubes}

Transforming the energy balance equation derived for a wall, assuming that the wall is an element with a lumped thermal capacity, the following is obtained:

$$
\tau_{\text {wall }} \frac{d T_{\text {wall }}}{d t}+T_{\text {wall }}=\frac{2 r_{i n} \alpha_{w} T_{w}+r_{\text {out }} \alpha_{o} T_{a}}{2 r_{\text {in }} \alpha_{w}+r_{\text {out }} \alpha_{o}}
$$

where the time constant, $\tau_{\text {wall }}$ is expressed as

$$
\tau_{\text {wall }}=\frac{\left(r_{o u t}^{2}-r_{\text {in }}^{2}\right) \rho_{\text {wall }} c_{w a l l}}{2 r_{\text {in }} \alpha_{w}+r_{\text {out }} \alpha_{o}} .
$$

The value of the waterwall tube time constant is highly dependent on the tube wall thickness and on the weighted heat transfer coefficient on the air side, which is much lower than on the water side.

The initial condition for Eq. (5) has the following form:

$$
\left.T_{w}\right|_{t=0}=T_{\infty}
$$

where $T_{\infty}$ denotes ambient temperature.

\subsection{Energy balance equation for air in the combustion chamber}

Transforming the energy balance equation for the $i$ th control volume on the air side, the following is obtained:

$$
\tau_{a} \frac{\partial T_{a}}{\partial t}+\frac{1}{N_{a}} \frac{\partial T_{a}}{\partial s^{+}}=\left(T_{w a l l}-T_{a}\right)
$$

where

$$
N_{a}=\frac{n_{t} \pi r_{o u t} \alpha_{o} L_{s}}{\dot{m}_{a} c_{p}} \quad \text { and } \quad \tau_{a}=\frac{A_{c} \rho_{a} c_{p, a}}{n_{t} \pi r_{o u t} \alpha_{o}}
$$


The initial and the boundary conditions are as expressed as

$$
\left.T_{a}\right|_{t=0}=T_{\infty} \text { and }\left.\quad T_{a}\right|_{s^{+}=0}=T_{\infty}
$$

Equation(8) with conditions (10) will be solved using the finite difference method. In the same way downcomers were modeled.

\section{Analysis of the possibility of using water tanks to fill the evaporator with hot water during start-up from the cold state}

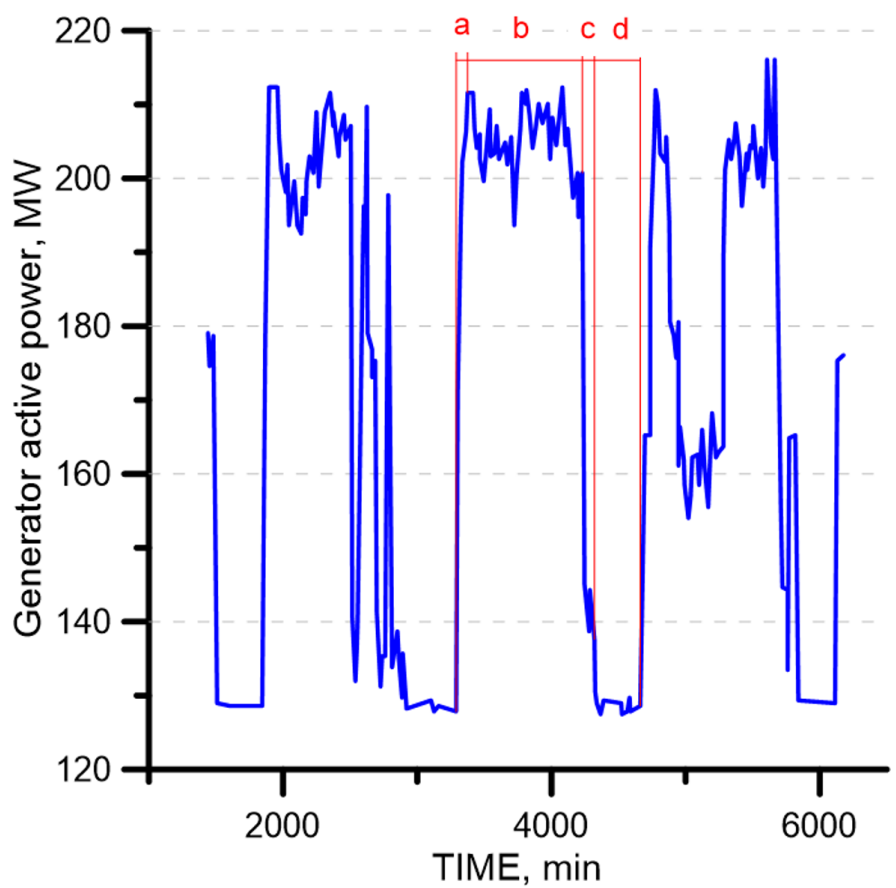

Figure 2: History of changes in power, fuel mass flow, and the boiler efficiency in a threeday operating cycle of the power unit of the power plant: a - increase in power from the minimum to the maximum value $1.5 \mathrm{~h}, 2015-06-1006: 45-08: 15, \mathrm{~b}-$ power unit operation under a nominal load during the day $14.25 \mathrm{~h}, 2015-06-10$ $08: 15-22: 30, \mathrm{c}$ - decrease in power from the maximum to the minimum value $1.5 \mathrm{~h}, 2015-06-10$ 22:30-2015-06-11 00:00, d - power unit operation under the minimum load during the night 6 h, 2015-06-11 00:00-06:00. 
Figure 2 presents charts of basic parameters of the power unit operation in the power plant. The presented period covers 5 days of the power unit continuous operation: from 2015-06-06 (00:00) to 2015-06-12 (08:00), Monday to Friday. Characteristic periods of the power unit operation (a, b, c, d) are marked in the Fig. 2.

Diagram of the power unit with a hot water storage tank, in the period of peak demand for electricity and low demand for electricity, are shown in Fig. 3. Pressure tanks may be used to flood the boiler evaporator with hot water during the power unit start-up from the cold state (Fig. 3a). Filling the evaporator and then the drum with the initial temperature $T_{w i}$ with hot water with temperature $T_{w i}+\Delta T_{w}$ (Fig. 4), the drum heating rate may be reduced in further stages of the start-up. If the start-up time is a bit shorter compared to the time obtained based on PN-EN 12952-3 standard, stresses on the edge of the hole in the drum-downcomer tube interface do not exceed permissible values [1-3]. If the boiler evaporator is heated at rates determined according to PN-EN 12952-3 standard, permissible stress values are exceeded on a part of the hole perimeter [4]. This may quickly give rise to cracks on the downcomer tube hole edge. The method of the boiler start-up proposed in [1-3], where the boiler evaporator is flooded with hot water, is safe. Unlike Standard PN-EN 12952-3, the method allows an abrupt rise in the working medium temperature in the drum at the beginning of the drum heating process. The water temperature in the boiler drum may be raised even up to $100^{\circ} \mathrm{C}$, which makes it possible to reduce the consumption of mazut fired in the boiler. In the start-up, first, phase the temperature of the medium is raised to the nominal temperature of about $315^{\circ} \mathrm{C}$ from $100^{\circ} \mathrm{C}$ but not from $20^{\circ} \mathrm{C}$ to $315^{\circ} \mathrm{C}$.

\subsection{Calculations of the water tank capacity}

Calculations of the capacity of hot water tanks was conducted for preliminary assumptions:

- absolute pressure: $p=0.7 \mathrm{MPa}$,

- saturation temperature: $T=164.9^{\circ} \mathrm{C}$,

- water density: $\rho_{w}=902.56 \mathrm{~kg} / \mathrm{m}^{3}$,

- power unit power: $200 \mathrm{MW}$,

- boiler output: $\dot{m}_{w}=650 \mathrm{t} / \mathrm{h}=180.5 \mathrm{~kg} / \mathrm{s}$,

- inner diameter of a single tank: $d_{i n}=3 \mathrm{~m}$. 

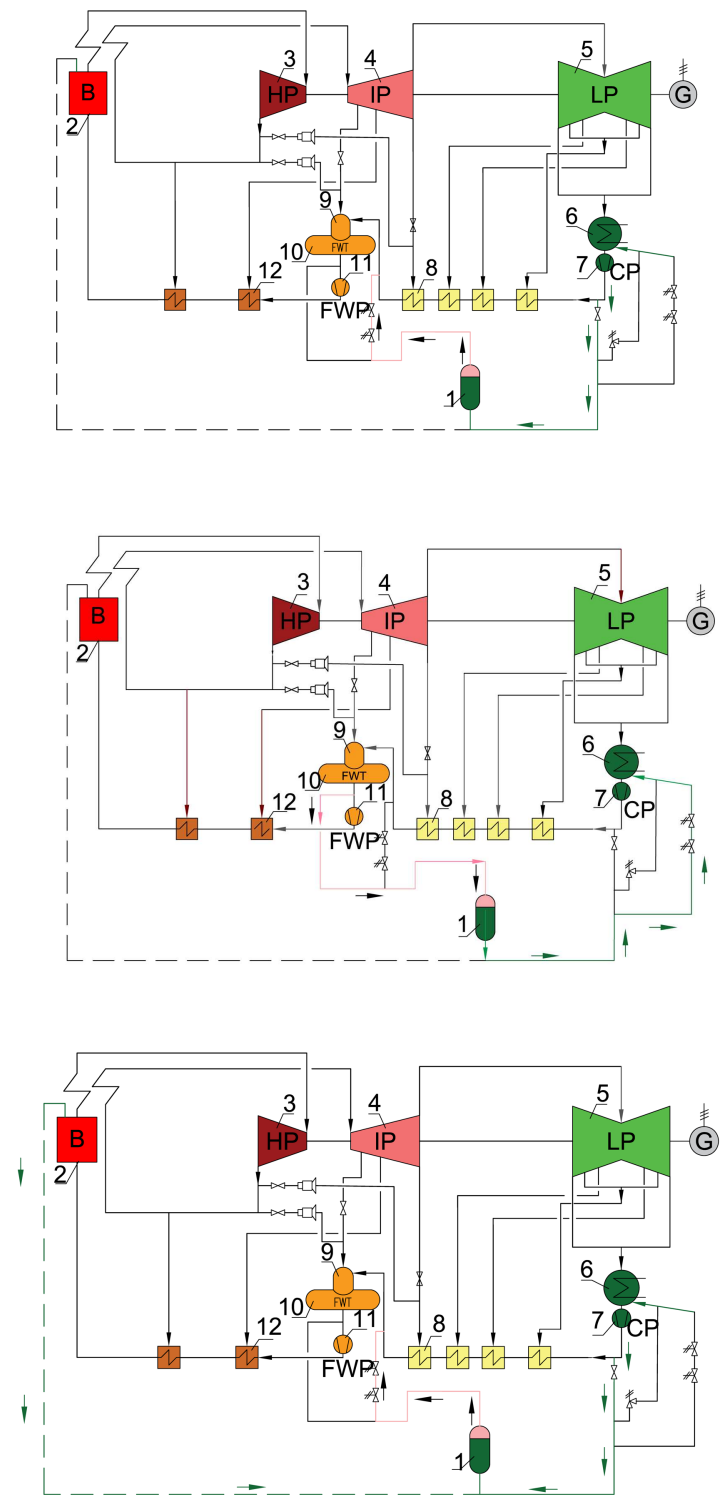

Figure 3: Diagram of the thermal power plant with storage of hot water: a) rapid increase in the power block, b) reduction of the power block and filling the storage tank with hot water, c) rapid start-up of the boiler from cold and warm state; 1 - heat storage tank, 2 - boiler, 3 - high-pressure turbine, 4 - intermediatepressure turbine, 5 - low-pressure turbine, 6 - condenser, 7 - condensate pump, 8 - low-pressure regenerative heaters, 9 - deaerator, 10 - feedwater tank, 11 feedwater pump, 12 - high-pressure regenerative heaters. 


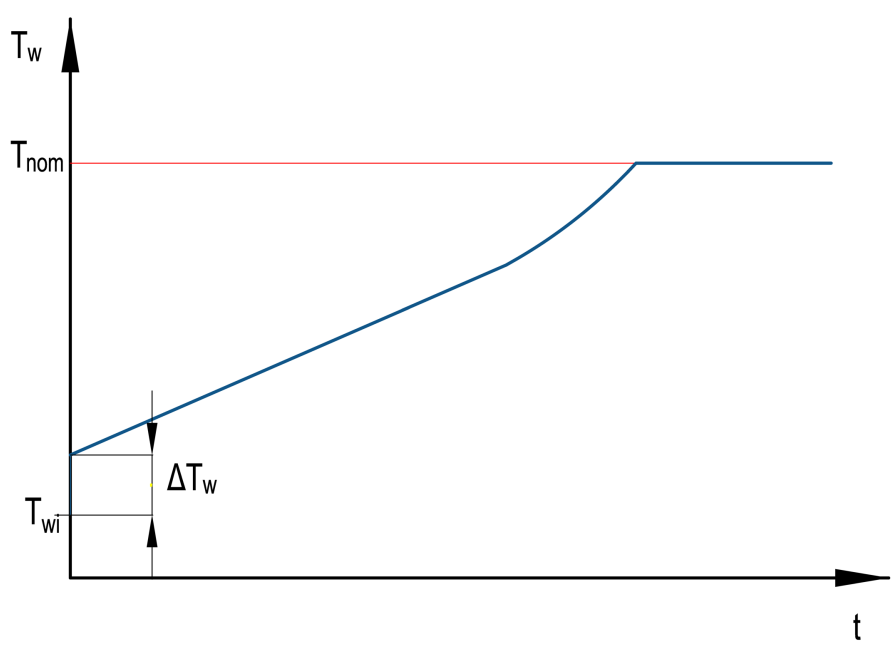

Figure 4: Proposed optimum change in the temperature of the medium in the drum.

It should be mentioned that the power unit generating capacity may be higher - it may reach as much as $225 \mathrm{MW}$ at the live steam mass flow of $680-700 \mathrm{t} / \mathrm{h}$. The results obtained from the analyses may be linearly extrapolated to higher or lower loads. The results calculations of the capacity of hot water tanks at different times of the boiler being fed from them shown in Tab. 1.

Table 1: Results for diameter $d_{i n}=3 \mathrm{~m}$.

\begin{tabular}{|c|c|c|l|c|c|}
\hline \multicolumn{2}{|c|}{ Tank dimensions } & $\begin{array}{l}\text { Time of } \\
\text { peak-demand } \\
\text { operation }\end{array}$ & $\begin{array}{l}\text { Water } \\
\text { volume }\end{array}$ & $\begin{array}{l}\text { Number } \\
\text { of } \\
\text { tanks }\end{array}$ \\
\hline Diameter & Height & Capacity & & & \\
\hline $\mathrm{m}$ & $\mathrm{m}$ & $\mathrm{m}^{3}$ & $\mathrm{~min}$ & $\mathrm{~m}^{3}$ & $\mathrm{pcs}$ \\
\hline \hline \multirow{3}{*}{3} & \multirow{3}{*}{25.5} & \multirow{3}{*}{180.25} & 30 & 360.09 & 2 \\
\cline { 4 - 6 } & & & 60 & 720.17 & 4 \\
\cline { 4 - 6 } & & & 120 & 1440.35 & 8 \\
\cline { 4 - 6 } & & & 240 & 2160.52 & 12 \\
\cline { 4 - 6 } & & & & 2880.69 & 16 \\
\hline
\end{tabular}


The following relations have been used to calculations of water required volume, $V_{w}$, and height of tanks, $H_{\text {tank }}$

$$
\begin{aligned}
& V_{w}=\frac{\dot{m}}{\rho_{w}} t_{\text {peak }}, \\
& H_{\text {tank }}=\frac{V_{w}}{n \frac{\pi d_{\text {in }}^{2}}{4}},
\end{aligned}
$$

where $n$ is the number of tanks. The tanks may be made of vertical vessels with stratification of cold and hot water and operating in a parallel system (Fig. 5). The hot water tanks may also be horizontal. In this case, they operate as a series-parallel system.

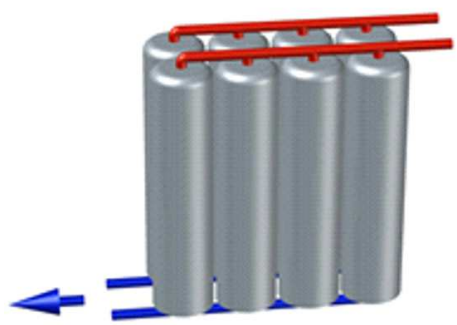

a)

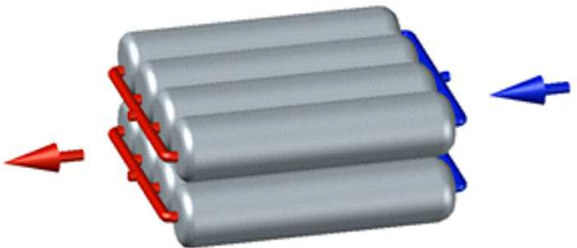

b)

Figure 5: Several configuration variants of the hot water tanks a) vertical, parallel configuration of tanks; b) horizontal, parallel configuration.

\subsection{Method of the power capacity determination for the power unit}

Mass flow rates and temperatures of water and steam were determined from solving a system of equations of mass and energy balance set for all components of the thermal power plant. An example of the control region for the boiler is shown in Fig. 6, presents simplified diagram of the boiler with intake of injection water from outside the control region boundary used to write the mass and energy balance equations.

The expressions for calculating the power of the turbine set in the night off-peak are:

- internal power generated in a high-pressure part of the turbine set

$$
\dot{Q}_{H P}=\dot{m}_{s}\left(h_{S H 5}^{\text {outlet }}-h_{I}\right)+\left(\dot{m}_{s}-\dot{m}_{I}\right)\left(h_{I}-h_{I I}\right),
$$




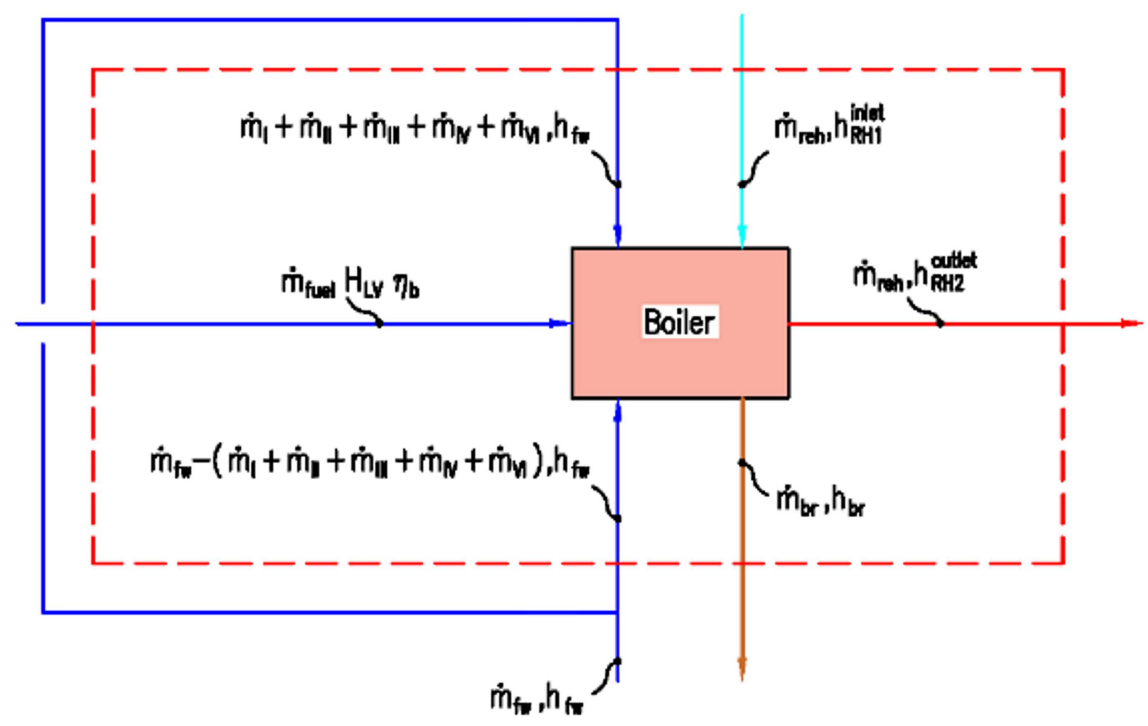

a)

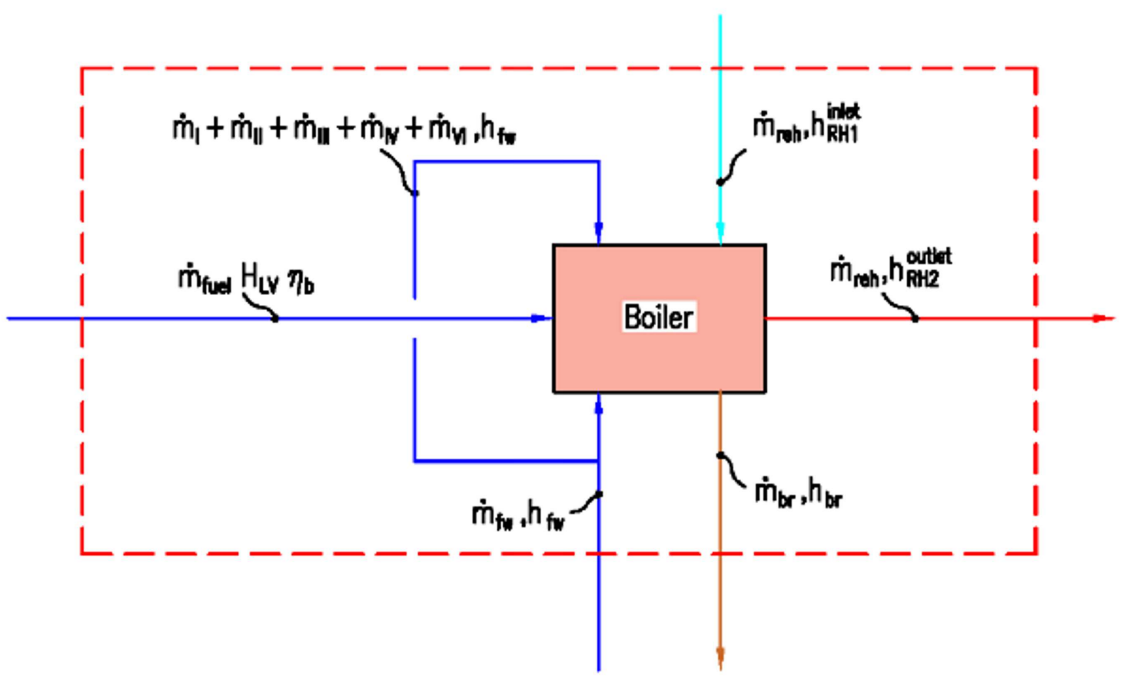

b)

Figure 6: Simplified diagram of the boiler a) intake of injection water beyond the balance boundary, b) intake of injection water and injection into steam temperature regulators are included inside the balance boundary. 
- internal power generated in an intermediate-pressure part of the turbine set

$$
\begin{aligned}
\dot{Q}_{I P} & =\dot{m}_{I P}\left(h_{I P}-h_{I I I}\right)+\left(\dot{m}_{I P}-\dot{m}_{I I I}\right)\left(h_{I I I}-h_{I V}\right)+ \\
& +\left(\dot{m}_{I P}-\dot{m}_{I I I}-\dot{m}_{I V}\right)\left(h_{I V}-h_{V}\right)+ \\
& +\left(\dot{m}_{I P}-\dot{m}_{I I I}-\dot{m}_{I V}-\dot{m}_{V}\right)\left(h_{V}-h_{V I}\right),
\end{aligned}
$$

- internal power generated in a low-pressure part of the turbine set

$$
\dot{Q}_{L P}=\dot{m}_{L P}\left(h_{L P}-h_{V I I}\right)+\left(\dot{m}_{L P}-\dot{m}_{V I I}\right)\left(h_{V I I}-h_{b l p}\right),
$$

- the total internal power of the turbine set

$$
\dot{Q}_{t}=\dot{Q}_{H P}+\dot{Q}_{I P}+\dot{Q}_{L P},
$$

- the relative drop in the power unit power

$$
\dot{Q}_{\text {proc }}=\frac{100 \dot{Q}_{t}}{\dot{Q}},
$$

- drop in power during the night off-peak hours

$$
S_{M}=100-\dot{Q}_{\text {proc }} .
$$

The energy balance equation for the example the control region for the boiler is given by

$\dot{m}_{f u e l} H_{L V} \eta_{b}+\dot{m}_{f w} h_{f w}+\dot{m}_{r e h} h_{R H 1}^{\text {inlet }}=\dot{m}_{s} h_{S H 5}^{\text {outlet }}+\dot{m}_{r e h} h_{R H 2}^{\text {outlet }}+\dot{m}_{b r} h_{b r}$.

The drop in the boiler output and in the power unit power in the night off-peak hours during the filling of the tank is shown Tab. 2.

The use of hot water accumulators increases the average efficiency of the power plant. The increase in efficiency occurs during the off-peak night hours when demand for electricity is low. The steam taken from the turbine bleed to heat water in hot water tanks does the work, on the section from the turbine inlet to the steam bleed. In this way, the steam taken in the bleed passes the main source of heat loss which is the turbine condenser. Such a method of improving the efficiency of Rankine cycle is also used in power plants through the use of regenerative heating of feed water or in combined heat and power plants for water heating in district heating 
Table 2: List of results - the drop in the boiler output and in the power unit power in the night off-peak hours during the filling of the tank (power capacity $206 \mathrm{MW}$ ).

\begin{tabular}{|c|c|c|c|c|c|}
\hline Item & $\begin{array}{l}\text { Number } \\
\text { of tanks }\end{array}$ & $\begin{array}{l}\text { Time of } \\
\text { filling the } \\
\text { tanks during } \\
\text { the night } \\
\text { off-peak } \\
\text { hours, h }\end{array}$ & $\begin{array}{l}\text { Water mass } \\
\text { flow to } \\
\text { tanks, } \mathrm{t} / \mathrm{h}\end{array}$ & $\begin{array}{l}\text { Boiler } \\
\text { output } \\
\text { during the } \\
\text { filling of } \\
\text { tanks, } \mathrm{t} / \mathrm{h}\end{array}$ & $\begin{array}{l}\text { Relative } \\
\text { drop in } \\
\text { power, } \%\end{array}$ \\
\hline 1 & \multirow{4}{*}{2} & 3 & 108.46 & 607.38 & 2.29 \\
\hline 2 & & 4 & 81.34 & 610.51 & 1.79 \\
\hline 3 & & 5 & 65.07 & 612.51 & 1.46 \\
\hline 4 & & 6 & 54.23 & 613.89 & 1.24 \\
\hline 5 & \multirow{4}{*}{4} & 3 & 216.91 & 596.99 & 3.96 \\
\hline 6 & & 4 & 162.67 & 601.80 & 3.19 \\
\hline 7 & & 5 & 130.15 & 605.05 & 2.66 \\
\hline 8 & & 6 & 108.46 & 607.38 & 2.29 \\
\hline 9 & \multirow{4}{*}{8} & 3 & 433.83 & 583.03 & 6.21 \\
\hline 10 & & 4 & 325.37 & 589.13 & 5.22 \\
\hline 11 & & 5 & 260.30 & 593.60 & 4.51 \\
\hline 12 & & 6 & 216.91 & 596.99 & 3.96 \\
\hline 13 & \multirow{4}{*}{12} & 3 & 650.75 & 574.21 & 7.63 \\
\hline 14 & & 4 & 488.06 & 580.46 & 6.62 \\
\hline 15 & & 5 & 390.45 & 585.30 & 5.84 \\
\hline 16 & & 6 & 325.37 & 589.13 & 5.22 \\
\hline
\end{tabular}

network. In the period of peak demand for electricity, the steam unit works with the efficiency typical for condensing regime. Low-pressure steam bleeds are closed to increase the power of the block. However, the hot water with temperature typical for normal block operation flows from storage tanks the degasser. The time-averaged efficiency of the block with hot water storage tanks is greater than the efficiency of the unit without hot water accumulators. Preliminary analysis of the economic viability of the use of the pressure accumulation of hot water has been presented in [5]. In year 2016 in Poland eight tanks of hot water (Tab. 2) were profitable if the price of $1 \mathrm{MWh}$ of electrical energy in peak will be higher than $240 \mathrm{PLN} / \mathrm{h}$ [5]. The experience of Western Europe power plant users shows that the cost of installing accumulators of hot water for increasing the power plant flexibility return in the period from one to two years. The thermodynamic and economic analysis of the power plant of the pressurized hot water storage tanks carried out in the paper is preliminary. The real 
benefits of using the accumulators can thoroughly be estimated after the construction of a pilot plant.

\section{Summary}

The results of the analysis of the $200 \mathrm{MW}$ power unit thermal system and of the thermal calculations lead to the following conclusions:

- The power unit maximum power capacity of $206 \mathrm{MW}$ may be raised during the period of peak demand for electricity by $7.32 \%(0.0732 \times$ $206 \mathrm{MW}=15 \mathrm{MW}$ )

- The period of the power unit operation with the raised maximum power capacity may last:

- 30 min at two tanks with the total capacity of $360.5 \mathrm{~m}^{3}$

- 60 min at four tanks with the total capacity of $721 \mathrm{~m}^{3}$

- 120 min at eight tanks with the total capacity of $1442 \mathrm{~m}^{3}$

- 180 min at twelve tanks with the total capacity of $2163 \mathrm{~m}^{3}$

- The maximum reduction in the power unit power capacity (which is 135 MW before the activation of the heat storage tanks) during the night off-peak hours is $16.27 \%(0.1627 \times 135 \mathrm{MW}=21.96 \mathrm{MW})$ at eight tanks with the total capacity of $1442 \mathrm{~m}^{3}$. The period in which the tanks are charged, and consequently the time of the power unit operation under a reduced load, is $3 \mathrm{~h}$.

- If eight water tanks with the total capacity of $1442 \mathrm{~m}^{3}$ are charged for $6 \mathrm{~h}$, the reduction in the power unit power capacity is $8.15 \%$ $(0.0815 \times 135 \mathrm{MW}=11 \mathrm{MW})$. If the water pressure tanks are discharged during $2 \mathrm{~h}$ period of peak demand for electricity, the increment in the power unit power capacity totals $7.32 \%$ (15 MW). This solution, which anticipates installation of 8 tanks charged for $6 \mathrm{~h}$ during the night off-peak period and discharged for $2 \mathrm{~h}$ in the peak period, is recommended to be used in practice.

- The tanks may be made as vertical structures with stratification of cold and hot water and operating in a parallel system. The hot water 
tanks may also be horizontal. In this case, they operate as a seriesparallel system.

- Hot water pressure tanks may also be used in power units participating in the automatic system of frequency and power control to ensure a sudden increase in the power unit power at any time of the day.

In order to shorten the start-up from the cold state, the boiler evaporator may be flooded with hot water from one of the pressure water tanks.

Received 24 October 2016

\section{References}

[1] Taler J., Dzierwa P., Taler D., Harchut P.: Optimization of the boiler start-up taking into account thermal stresses. Energy 92(2015), 1, 160170,DOI:10.1016/j.energy.2015.03.095.

[2] Dzierwa P., Taler D., Taler J., Trojan M.: Optimum heating of thick wall pressure components of steam boilers. In: Pro. ASME 2014 Power Conference POWER2014, July 28-31, 2014, Baltimore, Maryland, 1-9.

[3] Dzierwa P., Taler J.: Optimum heating of pressure vessels with hole. J. Pressure Vessels Technol. 137(2015), ASME, 011202-1-8/.

[4] Polish Standard PN-EN 12952-3: Water-tube boilers and auxiliary installations. Part 3: Design and calculation for pressure parts. PKN, Warsaw 2004.

[5] Taler J., Trojan M., Taler D., Dzierwa P., Kaczmarski K., Liszka M.: Improvement of power unit flexibility using pressure accumulation of hot water. Thermal turbines. Theory, Constractions and Operations. Wydawnictwo Politechniki Śląskiej, Gliwice 2016, 167-179. 